\title{
Study on Extraction Technology and Stability of Red Pigment in Red Plumeria
}

\author{
Tingqin Wang ${ }^{1, \dagger}$, Qianru $\mathrm{Li}^{2, \dagger}$, Bei Cai ${ }^{1}$, Yunying Yang ${ }^{3}$ * \\ ${ }^{1}$ College of Coastal Agricultural Sciences, Guangdong Ocean University, Zhanjiang, China \\ ${ }^{2}$ College of Fisheries, Guangdong Ocean University, Zhanjiang, China \\ ${ }^{3}$ College of Horticulture and Landscape, Guangdong Polytechnic of Science and Trade, Guangzhou, China
}

\author{
Email address: \\ 76589198@qq.com (Yunying Yang) \\ ${ }^{*}$ Corresponding author \\ $\dagger$ Tingqin Wang and Qianru Li are co-first authors.
}

\section{To cite this article:}

Tingqin Wang, Qianru Li, Bei Cai, Yunying Yang. Study on Extraction Technology and Stability of Red Pigment in Red Plumeria. Agriculture, Forestry and Fisheries. Vol. 10, No. 4, 2021, pp. 140-151. doi: 10.11648/j.aff.20211004.14

Received: June 15, 2021; Accepted: June 28, 2021; Published: July 13, 2021

\begin{abstract}
Background: Pigments, especially for those red color are widely used in various products and are closely related to human health, however, the study on screening optimal conditions for extracting red pigment from red frangipani is less reported. Objective: This study is aimed to decipher the effects of these factors on the stability of the pigment. Method: We developed an optimized extraction method of red pigment from Plumeria rubra L leaves through different combinations of extractants, incubation time and temperature. Results: Results show that the largest productivity of red pigment is found under the condition of $10 \%$ citric acid as extractant at $80^{\circ} \mathrm{C}$ for $90 \mathrm{~min}$ compared to other conditions. The pigment is sensitive to high light and appears to have strong reducibility rather than oxidability. The pigments production is also sensitive to $\mathrm{pH}$ value, as well as metal ion strength, such as $\mathrm{Al}^{3+}, \mathrm{Cu}^{2+}, \mathrm{Fe}^{3+}, \mathrm{Mn}^{2+}, \mathrm{Zn}^{2+}, \mathrm{K}^{+}, \mathrm{Mg}^{2+}, \mathrm{Na}^{+}$, and $\mathrm{Ca}^{2+}$, whereas the production is inhibited by adding sucrose, salt and soluble starch. Conclusion: We concluded that red pigment is sensitive to external environmental stimulus and internal ion and carbohydrates concentrations, among these factors, a combination of $10 \%$ citric acid extranctant together with $80^{\circ} \mathrm{C}$ for 90 min treatments ensures to obtain the largest productivity of red pigment. This study provides a fundamental basis for the production of natural red plumeria red pigment and the screening for edible pigment varieties.
\end{abstract}

Keywords: Productivity, Plumeria rubra L, Pigment, Stability, Extract

\section{Introduction}

Pigments are extensively applied in various products and are closely related to our health. Nowadays, increasing attention has been paid on the security issues of pollution-free, healthy, environmental protection, and the safety of the use of pigments. In this regard, it has been made great efforts to develop natural pigments, instead of artificial pigments in terms of food, cosmetics and other industries [1]. Although natural pigments have the advantages of high safety, natural coloring, and easy to use, they are sensitive to various external factors (such as temperature, humidity, etc.), and their features to maintain stability is undesirable [2-4]. Even though there are abundant natural pigment resources in China, it is still urgent to need overseas seed companies to provide most of the excellent natural pigment sources. However, imported pigments are not only costly, but also it cannot guarantee the normal supply of provenance. Therefore, natural pigment raw materials insufficient supply increases the production cost of related products [3]. Therefore, expanding the source of natural pigments is of great significance to the industry of natural pigments in China.

Among various natural pigments, plant-derived pigments are very abundant and have unique physiological functions, therefore, which are regard as the primary option for modern natural pigments industries. Notably, among these natural pigments, red pigment is a very important type, of which the bright red color is helpful to stimulate the brain, a key component of analeptic, can also promote appetite [2, 4]. At present, extensive attempts on the research of red pigment 
extraction technology and stability in rose [5], gerbera [6] and camellia [7] were reported using the red plumeria as the raw material. However, specific reports on extracting red pigment and its stability were less documented.

Red plumeria (Plumeria rubra L), also known as staghorn tree, thumping hammer flower, egg yolk flower, Burmese gardenia, big season flower, etc. [8-10]. Red frangipani, mostly small trees or shrubs, are native to tropical regions of the Americas such as Venezuela, Mexico and the West Indies $[11,12]$. In some countries, red plumeria is commonly applied to make perfume and cosmetic raw materials as well as some food additives. Therefore, it is increasingly popular to make tea or eaten after dehydration in some cities of China, such as Fujian, Guangdong, Guangxi, and Yunnan. The trend has the promising prospect towards extensive development and utilization [13]. Thereby, it is a natural pigment resource, thanks of its bright red and beautiful flowers, that worth exploring and developing in red frangipani.

This study is aimed to provide the solution for the further expand the market of natural red plumeria red pigment, as well as the development of China's natural edible pigment varieties and pigment commodity industry. We systematically explored the extraction and stability of red frangipani red pigment, figure out the optimal extraction method of red frangipani pigment, and uncover the effects of external factors such as light conditions, $\mathrm{pH}$, reducing agents, oxidants, various metal ions and three common food additives on stability of red plumeria red pigment.

\section{Materials and Methods}

\subsection{Materials and Growth Conditions}

The red frangipani was collected from the main campus of Guangdong Ocean University, China. The petal of uniform shape with red color was used in this study.

The pretreatment procedure for extraction of red frangipani was as follows: take fresh and clean red frangipani, cut off the yellow parts of the petals, keep the red parts, and remove the defective petals. Wash the petals and dry them. Place it in the baking tray of the oven and dry at a temperature of $80^{\circ} \mathrm{C}$. After drying, use a coffee grinder to grind it into a fine powder and bottle it for later use.

\subsection{Spectral Characteristics of Red Plumeria Red Pigment}

$\sim 0.01 \mathrm{~g}$ dried petal powder of red frangipani in a test tube were taken into a total of 24 copies, followed by $10 \mathrm{~mL}$ of distilled water and shake was added, then cooled down at room temperature for $30 \mathrm{~min}$, and then filtered it through a $0.45 \mathrm{~m}$ PTFE filter. The filtrate was transferred to a $50 \mathrm{~mL}$ volumetric flask maintaining a constant volume with distilled water. The final red plumeria red pigment extract was obtained. Using distilled water as a blank solution, the absorbance was measured at 280-350 nm with an ultraviolet spectrophotometer at room temperature. The recorded OD value was analyze to examine the optimal absorption wavelength, so that the point where the absorption value reaches the peak.

\subsection{System Construction for Red Pigment Extraction from Red Plumeria}

\subsubsection{Screening Extractants}

To screen the extractants, we took $\sim 0.01 \mathrm{~g}$ of dried petal powder of red frangipani in a test tube, a total of 21 copies ( 7 levels, 3 repetitions), and then added $10 \mathrm{~mL}$ ethyl acetate, 10 $\mathrm{mL}$ acetone, $10 \mathrm{~mL}$ absolute ethanol, $10 \mathrm{~mL}$ distilled water, 10

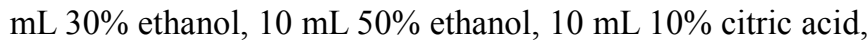
followed by brief shaking. It was then cooled down at room temperature for $30 \mathrm{~min}$, and filtered as mentioned above. The color of the extract and the extraction conditions were compared with each other to find the optimal extractant.

\subsubsection{Screening Extraction Concentration}

To uncover the optimal extraction concentration, we took $\sim 0.01 \mathrm{~g}$ dried petal powder of red frangipani in a test tube into a total of 21 copies ( 7 levels, 3 repetitions), and then added 10 $\mathrm{mL}$ of extractant with concentration of $1 \%, 5 \%, 10 \%, 15 \%$, $20 \%, 25 \%$ and $30 \%$ respectively, with brief shaking. The mixture was then cooled down at room temperature for $30 \mathrm{~min}$, filtered, and the filtrate was transferred to a $50 \mathrm{~mL}$ volumetric flask maintaining constant volume with distilled water. We also used the extractant as a blank solution, simultaneously measured the OD value with the suitable absorption wavelength in the ultraviolet spectrophotometer to determine the best extractant concentration.

\subsubsection{Screen the pH of the Extractant}

The optimal concentration of the pigment extraction solvent, obtained by the above method is prepared with a low concentration hydrochloric acid solution and a sodium hydroxide solution to keep the $\mathrm{pH}$ of the solution as 1, 2, 3, 4, $5,6,7,8,9$ and 10 , respectively. We took $0.01 \mathrm{~g}$ of dried petal powder of red frangipani in a test tube, a total of 33 copies (11 levels, 3 repetitions), and then added $10 \mathrm{~mL}$ of the best extractant with different $\mathrm{pH}$ accordingly followed by gently shaking. The solution was then cooled down at room temperature for $30 \mathrm{~min}$, and filtered as mentioned above. After that, the filtrate was transferred to a $50 \mathrm{~mL}$ volumetric flask and kept constant volume with distilled water. We used the extractant as a blank solution, and measured the OD value with the optimal absorption wavelength in the ultraviolet spectrophotometer to determine the best extraction $\mathrm{pH}$.

\subsubsection{Screening Extraction Temperature}

To screen extraction temperature, we took $\sim 0.01 \mathrm{~g}$ of dried petal powder of red frangipani in a test tube, i.e., a total of 24 parts ( 8 levels, 3 repetitions), and added $10 \mathrm{~mL}$ of the best extractant and shake. It was then placed in room temperature, $30^{\circ} \mathrm{C}, 40^{\circ} \mathrm{C}, 50^{\circ} \mathrm{C}, 60^{\circ} \mathrm{C}, 70^{\circ} \mathrm{C}, 80^{\circ} \mathrm{C}$ and $90^{\circ} \mathrm{C}$ water baths for $30 \mathrm{~min}$, and filtered sequentially. Followed by that, we transferred the cooled filtrate to a $50 \mathrm{~mL}$ volumetric flask and make up to volume, we used the extractant as a blank solution, and measured the OD value with the best absorption wavelength in an ultraviolet spectrophotometer to determine the optimal extraction temperature. 


\subsubsection{Screening and Extraction Time}

Take $0.01 \mathrm{~g}$ of dried petal powder of red frangipani in a test tube, a total of 18 parts ( 6 levels, 3 repetitions), and then added $10 \mathrm{~mL}$ of the pigment extraction solvent with brief shaking. Under the optimal extraction temperature obtained by the above method, the extraction duration is set to $15 \mathrm{~min}, 30 \mathrm{~min}$, $45 \mathrm{~min}, 60 \mathrm{~min}, 75 \mathrm{~min}$ and $90 \mathrm{~min}$ and then filtered with $0.45 \mathrm{~m}$ PTFE filter. Transfer the cooled filtrate to a $50 \mathrm{~mL}$ volumetric flask and make up to volume. Using the extractant as a blank solution, measure the OD value with the best absorption wavelength in an ultraviolet spectrophotometer to find the optimal extraction duration.

\subsection{Orthogonal Test}

The tests mentioned above for extracting pigment conditions are all single-factor tests. It is of great interest to determine whether there is an interaction between the extraction factors, with an effect on the extraction of red pigment from red plumeria. Therefore, a 3-factor 3-level orthogonal test of L9 $\left(3^{4}\right)$ was set to select the optimal conditions for extracting red pigment from red plumeria. In this regard, we used the extractant as a blank solution, and the OD value was simultaneously measured with the optimal absorption wavelength in an ultraviolet spectrophotometer. The optimal conditions for extracting the pigment were selected as shown in Table 1.

Table 1. Orthogonal test on three factors for red frangipani extraction.

\begin{tabular}{llll}
\hline Factor levels & A (Con. $/ \%)$ & B (Temp. $\left./{ }^{\circ} \mathbf{C}\right)$ & C (Time/min) \\
\hline 1 & 1 & 70 & 45 \\
2 & 5 & 80 & 60 \\
3 & 10 & 90 & 90 \\
\hline
\end{tabular}

\subsection{Red Plumeria Red Pigment Stability Study}

The red plumeria red pigment stock solution is prepared by combining the optimal extraction conditions obtained by the above method.

\subsubsection{Effect of Light on Red Pigment of Red Frangipani}

Measure $100 \mathrm{~mL}$ of red plumeria red pigment extract in a $200 \mathrm{~mL}$ glass tube with a tap, 6 portions in total, seal and label it. Distribute it evenly in black plastic sealed bags under either natural outdoor light or darkness. Within 7 days, we determined the OD value at the optimal absorption wavelength of the pigment every day and observed the color change of solution.

\subsubsection{Effect of pH on Red Pigment of Red Plumeria}

A solution with a $\mathrm{pH}$ of $1 \sim 10$ was prepared with $1 \mathrm{~mol} / \mathrm{L}$ $\mathrm{HCl}, 1 \mathrm{~mol} / \mathrm{L} \mathrm{NaOH}, 0.1 \mathrm{~mol} / \mathrm{L} \mathrm{HCl}$ and $0.1 \mathrm{~mol} / \mathrm{L} \mathrm{NaOH}$. We took $5 \mathrm{~mL}$ of pigment stock solution, and added sequentially 3 $\mathrm{mL}$ solutions with different $\mathrm{pH}$ values as mentioned above, and then shake. After incubation for $30 \mathrm{~min}$, the OD value was measured with the optimal absorption wavelength.

\subsubsection{Effect of Reducing Agent on Red Pigment of Red Plumeria}

To unravel the effect of reducing agent on red pigment of red plumeria, we transferred $3 \mathrm{~mL}$ of $\mathrm{NaHSO}_{3}$ solution of different concentrations $(0.05 \mathrm{~mol} / \mathrm{L}, 0.10 \mathrm{~mol} / \mathrm{L}, 0.15 \mathrm{~mol} / \mathrm{L}$, $0.20 \mathrm{~mol} / \mathrm{L}$, and $0.25 \mathrm{~mol} / \mathrm{L}$ ) into $5 \mathrm{~mL}$ of pigment stock solution and briefly shake. After incubation for $30 \mathrm{~min}$, we recorded the color change of the solution and measured the OD value at the optimal absorption wavelength.

\subsubsection{Effect of Oxidants on Red Pigment of Red Plumeria}

In total, $3 \mathrm{~mL}$ of $\mathrm{H}_{2} \mathrm{O}_{2}$ solutions of different concentrations $(4 \%, 8 \%, 12 \%, 16 \%, 20 \%)$ was transferred into $5 \mathrm{~mL}$ of pigment stock solution and shake. After incubation for $30 \mathrm{~min}$, we observed the color change of the solution and measured the OD values at the optimal absorption wavelength.

\subsubsection{Effect of Various Metal Ions on Red Pigment of Red Plumeria}

Effect of various metal ions on red pigment of red plumeria was examined through transferring $3 \mathrm{~mL}$ of $0.1 \mathrm{~mol} / \mathrm{L}$ of various metal ion solutions $\left(\mathrm{Fe}^{3+}, \mathrm{Ca}^{2+}, \mathrm{Mn}^{2+}, \mathrm{Mg}^{2+}, \mathrm{Na}{ }^{+}\right.$, $\mathrm{Cu}^{2+}, \mathrm{Zn}^{2+}, \mathrm{Al}^{3+}, \mathrm{K}^{+}$) into $5 \mathrm{~mL}$ of pigment stock solution and shake. After incubation for $30 \mathrm{~min}$, we recorded the color change of the solution and measured the OD values at the optimal absorption wavelength.

\subsubsection{Effect of Common Food Additives on Red Pigment of Red Plumeria}

To examine the effect of common food additives on red pigment of red plumeria, we transferred $3 \mathrm{~mL}$ of sucrose solutions of different concentrations $(0.5 \%, 1 \%, 1.5 \%, 2.0 \%$, $2.5 \%$, and $3.0 \%$ ) into $5 \mathrm{~mL}$ of pigment stock solution and briefly shake. After incubation for $30 \mathrm{~min}$, we observed the color change of the solution and measure the OD value at the optimal absorption wavelength.

For different concentrations $(0.5 \%, 1 \%, 1.5 \%, 2.0 \%, 2.5 \%$, and $3.0 \%$ ) of common salt solution, $3 \mathrm{~mL}$ solution was transferred to $5 \mathrm{~mL}$ of pigment stock solution and shake. After incubation for $30 \mathrm{~min}$, we recorded the color change of the solution and measure the OD value at the optimal absorption wavelength.

In order to examine the effects of soluble starch solutions, 3 $\mathrm{mL}$ different concentrations $(0.5 \%, 1 \%, 1.5 \%, 2.0 \%, 2.5 \%$, and $3.0 \%$ ) were transferred into $5 \mathrm{~mL}$ of pigment stock solution and shake. After incubation for $30 \mathrm{~min}$, we recorded the color change of the solution and measure the OD value at the optimal absorption wavelength.

\subsection{Statistical Analysis}

LSD method was employed in the DPS data processing system software to perform statistical analysis on the data. Figures were generated via SigmaPlot software.

\section{Results}

\subsection{Spectral Characteristics of Red Pigment in Red Plumeria}

As shown in Figure 1, from the wavelength of $280 \mathrm{~nm}$ to $350 \mathrm{~nm}$, the peak is reached at $300 \mathrm{~nm}$, and the absorbance 
values on both sides of $300 \mathrm{~nm}$ gradually decreased. Results also show that among the 8 wavelengths, there are extremely significant differences between each wavelength except 330 $\mathrm{nm}$ and $290 \mathrm{~nm}$ (Table 2). At a wavelength of $300 \mathrm{~nm}$, the mean value is greater than other wavelength and is significantly different from other wavelengths $(P<0.05)$. These evidences suggest that the optimal absorption wavelength for red pigment in red plumeria is around $300 \mathrm{~nm}$.

Table 2. Significant difference analysis of the absorbance value of red egg pigment at different wavelengths.

\begin{tabular}{llll}
\hline $\begin{array}{l}\text { wavelength } \\
\text { (nm) }\end{array}$ & Absorbance & $\mathbf{5 \%}$ sig. levels & $\mathbf{1 \%}$ sig. levels \\
\hline 300 & $0.9263 \pm 0.0116$ & $\mathrm{a}$ & $\mathrm{A}$ \\
310 & $0.8977 \pm 0.0032$ & $\mathrm{~b}$ & $\mathrm{~B}$ \\
320 & $0.8100 \pm 0.0090$ & $\mathrm{c}$ & $\mathrm{C}$ \\
330 & $0.6840 \pm 0.0040$ & $\mathrm{~d}$ & $\mathrm{D}$ \\
290 & $0.6787 \pm 0.0059$ & $\mathrm{~d}$ & $\mathrm{D}$ \\
340 & $0.5330 \pm 0.0056$ & $\mathrm{e}$ & $\mathrm{E}$ \\
350 & $0.3910 \pm 0.0046$ & $\mathrm{f}$ & $\mathrm{F}$ \\
280 & $0.2297 \pm 0.0035$ & $\mathrm{~g}$ & $\mathrm{G}$ \\
\hline
\end{tabular}

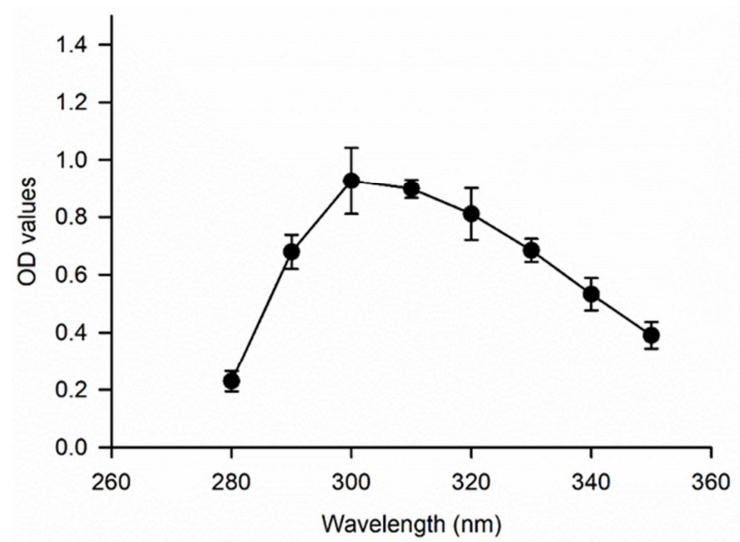

Figure 1. Absorbance curve of red pigment in red egg flower at different wavelengths. Means are values $\pm S E(n=3)$.

\subsection{Extraction Process and Stability of Red Pigment from Red Plumeria}

The red pigment of red plumeria is insoluble in ethyl acetate, acetone, and absolute ethanol, but it is soluble in distilled water, $30 \%$ ethanol, 50\% ethanol, and 10\% citric acid (Table 3). Therefore, these suggest that red plumeria red pigment could be a water-soluble pigment. The red pigment of red frangipani is extracted with distilled water, the dissolution speed is rapid, and the extraction is also sufficient. The initial pigment solution is pink, while the pigment is unstable, and the color of the solution will gradually fade down after a period of time. When extracting red plumeria red pigment with $30 \%$ ethanol and $50 \%$ ethanol, the speed is also fast and sufficient. The color of the solution is similar to the color of petals, which is light pink. However, when $10 \%$ citric acid was used to extract the pigment, the dissolved speed was fast, the color of the pigment solution was obviously the darkest. In addition, the solution color was not altered after incubation for a period of time. Therefore, the optimal extracting agent for red pigment of red plumeria, determined in this study is citric acid.
The absorption curve reached the absorption peak when the citric acid concentration was $10 \%$ (Figure 2A). The red pigment absorption value of red plumeria increases with the increase of citric acid concentration. After the citric acid concentration is $10 \%$, the citric acid concentration increased while the absorbance value decreased. The absorbance value of $10 \%$ citric acid solution is significantly greater than that of other concentration solutions (Table 4). At the same time, the average absorbance value of $10 \%$ citric acid solution appear to be the largest, suggesting the best treatment at this condition. Therefore, the optimal concentration of citric acid to extract red pigment from red frangipani is around $10 \%$.

Table 3. Color alteration of red pigment of red egg flower treated with different extractants.

\begin{tabular}{llll}
\hline Extractants & Filter residue & Filtrate & Extraction effect \\
\hline Distilled water & White & Light pink & Easy \\
$30 \%$ ethanol & White & Light pink & Easy \\
$50 \%$ ethanol & White & Light pink & Easy \\
$10 \%$ citric acid & White & Light pink & Easy \\
ethyl acetate & Pink & Colorless & Difficult \\
$100 \%$ ethanol & Pink & Colorless & Difficult \\
acetone & Pink & Colorless & Difficult \\
\hline
\end{tabular}

Table 4. Significant difference analysis between different concentrations of extractant treatment.

\begin{tabular}{llll}
\hline $\begin{array}{l}\text { extraction } \\
\text { concentration (\%) }\end{array}$ & Absorbance & $\mathbf{5 \%}$ sig. levels & $\begin{array}{l}\mathbf{1 \%} \text { sig. } \\
\text { levels }\end{array}$ \\
\hline 10 & $0.8720 \pm 0.0056$ & $\mathrm{a}$ & $\mathrm{A}$ \\
5 & $0.8143 \pm 0.0059$ & $\mathrm{~b}$ & $\mathrm{~B}$ \\
1 & $0.7960 \pm 0.0020$ & $\mathrm{c}$ & $\mathrm{C}$ \\
15 & $0.7827 \pm 0.0125$ & $\mathrm{~d}$ & $\mathrm{C}$ \\
20 & $0.7540 \pm 0.0040$ & $\mathrm{e}$ & $\mathrm{D}$ \\
25 & $0.7357 \pm 0.0108$ & $\mathrm{f}$ & $\mathrm{E}$ \\
30 & $0.7210 \pm 0.0036$ & $\mathrm{~g}$ & $\mathrm{E}$ \\
\hline
\end{tabular}

In the range of $\mathrm{pH} \quad 1 \sim 6$, the absorption value gradually increases to the peak and then gradually decreases (Figure 2B). The first absorption peak is at the original $\mathrm{pH}$ solution. In the range of $\mathrm{pH} 6 \sim 10$, there is another absorption peak, but the peak of the highest peak is significantly lower than the peak of the highest peak of the first absorption peak. In Table 5, when the $\mathrm{pH}$ value is low, the pigment solution preferably retains the original color. When the $\mathrm{pH}$ value gradually increases, the color of the pigment solution changes, the original color becomes lighter to none, and then changes to other colors. This evidence shows that as the $\mathrm{pH}$ value increases, the pigment is degraded. Therefore, weak acid and alkaline extractants are not suitable for extracting red pigment from red plumeria.

The absorbance of the original $\mathrm{pH}$ solution is significantly different from that of other $\mathrm{pH}$ solutions (Table 5). Results imply that different $\mathrm{pH}$ values could alter the extraction effect of the pigment solution, and notably, the extraction effect is less than the original $\mathrm{pH}$ solution. Therefore, we proposed that given that does not adjust the $\mathrm{pH}$ value for extraction, the best option is a citric acid solution.

As the extraction temperature increases, the red plumeria red pigment's absorbance value gradually increases (Figure $2 \mathrm{C})$. At $80^{\circ} \mathrm{C}$, the absorbance value reaches the maximum. Subsequently, as the temperature increases, the absorbance 
value decreases. In Table 6 , the difference between the treatment with a temperature of $80^{\circ} \mathrm{C}$ and other temperature treatments is significant. At the same time, the maximum mean value of the measured absorbance is at a temperature of $80^{\circ} \mathrm{C}$, so this process is optimal. In summary, the optimal extraction temperature for the extraction of red pigment from red plumeria is $80^{\circ} \mathrm{C}$. The red plumeria red pigment's absorbance value gradually increased with the prolonged time, then suddenly dropped at $75 \mathrm{~min}$, and rised again at $90 \mathrm{~min}$ (Figure 2D). The OD values under $90 \mathrm{~min}$ treatment is very significantly different from that at $15 \mathrm{~min}, 30 \mathrm{~min}, 45 \mathrm{~min}$, and $75 \mathrm{~min}$, but not significantly different from that at $60 \mathrm{~min}$ (Table 7). Moreover, the maximum average value of the absorbance measured by the pigment solution is at $90 \mathrm{~min}$, suggesting that optimal treatment time of the pigment could be $90 \mathrm{~min}$.

Table 5. Results of red egg anthocyanin extracted by different $\mathrm{pH}$ value extractants.

\begin{tabular}{lllll}
\hline citric acid pH & Solution color & Absorbance & 5\% sig. levels & 1\% sig. levels \\
\hline Orig. pH (ck) & Pink & $0.8707 \pm 0.0040$ & $\mathrm{a}$ & $\mathrm{A}$ \\
2 & Pink & $0.8410 \pm 0.0026$ & $\mathrm{~b}$ & $\mathrm{c}$ \\
1 & Pink & $0.8283 \pm 0.0031$ & $\mathrm{~d}$ & $\mathrm{C}$ \\
8 & Yellow & $0.8080 \pm 0.0026$ & $\mathrm{de}$ & $\mathrm{D}$ \\
3 & Pink & $0.8023 \pm 0.0038$ & $\mathrm{e}$ & $\mathrm{DE}$ \\
7 & Light yellow & $0.7963 \pm 0.0035$ & $\mathrm{f}$ & $\mathrm{E}$ \\
4 & colorless & $0.7813 \pm 0.0051$ & $\mathrm{~g}$ & $\mathrm{~F}$ \\
9 & Light yellow & $0.7370 \pm 0.0040$ & $\mathrm{~h}$ & $\mathrm{G}$ \\
5 & colorless & $0.7157 \pm 0.0055$ & $\mathrm{i}$ & $\mathrm{H}$ \\
10 & Dark yellow & $0.7053 \pm 0.0067$ & $\mathrm{j}$ \\
6
\end{tabular}

Table 6. Results of red egg anthocyanin extracted by different temperature conditions.

\begin{tabular}{llll}
\hline Temperature $\left({ }^{\circ} \mathbf{C}\right)$ & Absorbance & 5\% sig. levels & 1\% sig. levels \\
\hline 80 & $0.9087 \pm 0.0060$ & a & A \\
90 & $0.8940 \pm 0.0030$ & b & B \\
70 & $0.8883 \pm 0.0015$ & bc & BC \\
60 & $0.8863 \pm 0.0070$ & bcd & BC \\
50 & $0.8833 \pm 0.0042$ & cd & BC \\
40 & $0.8807 \pm 0.0021$ & cd & C \\
30 & $0.8793 \pm 0.0025$ & d & C \\
25 (room temperature) & $0.8613 \pm 0.0060$ & e & D \\
\hline
\end{tabular}

Table 7. Significance analysis among different extraction time treatments.

\begin{tabular}{llll}
\hline Time (min) & Absorbance & 5\% sig. levels & 1\% sig. levels \\
\hline 90 & $0.9247 \pm 0.0032$ & $\mathrm{a}$ & $\mathrm{A}$ \\
60 & $0.9150 \pm 0.0075$ & $\mathrm{ab}$ & $\mathrm{AB}$ \\
45 & $0.9130 \pm 0.0066$ & $\mathrm{~b}$ & $\mathrm{AB}$ \\
30 & $0.9087 \pm 0.0060$ & $\mathrm{~b}$ & $\mathrm{~B}$ \\
75 & $0.8900 \pm 0.0062$ & $\mathrm{c}$ & $\mathrm{C}$ \\
15 & $08243 \pm 0.0055$ & $\mathrm{~d}$ & $\mathrm{D}$ \\
\hline
\end{tabular}

Table 8. Statistical analysis on significance and range according to orthogonal test results.

\begin{tabular}{|c|c|c|c|c|c|c|}
\hline \multirow{2}{*}{ \# Number } & \multicolumn{3}{|c|}{ Treatment methods } & \multirow{2}{*}{ Absorbance } & \multirow{2}{*}{$5 \%$ sig. levels } & \multirow{2}{*}{$1 \%$ sig. levels } \\
\hline & A (Con./\%) & B $\left(\right.$ Temp $\left./{ }^{\circ} \mathrm{C}\right)$ & C (Time/min) & & & \\
\hline 1 & 1 & 1 & 1 & 0.8610 & $\mathrm{~d}$ & $\mathrm{C}$ \\
\hline 2 & 1 & 2 & 2 & 0.9060 & $\mathrm{abc}$ & $\mathrm{AB}$ \\
\hline 3 & 1 & 3 & 3 & 0.9097 & $\mathrm{ab}$ & $\mathrm{AB}$ \\
\hline 4 & 2 & 2 & 3 & 0.9160 & $\mathrm{a}$ & A \\
\hline 5 & 2 & 3 & 1 & 0.8953 & $\mathrm{c}$ & B \\
\hline 6 & 2 & 1 & 2 & 0.8517 & $\mathrm{~d}$ & $\mathrm{C}$ \\
\hline 7 & 3 & 3 & 2 & 0.9153 & $\mathrm{a}$ & A \\
\hline 8 & 3 & 1 & 3 & 0.9117 & $\mathrm{ab}$ & $\mathrm{AB}$ \\
\hline 9 & 3 & 2 & 1 & 0.9010 & bc & $\mathrm{AB}$ \\
\hline k1 & 0.8922 & 0.8748 & 0.8858 & & & \\
\hline k2 & 0.8877 & 0.9077 & 0.8910 & & & \\
\hline k3 & 0.9093 & 0.9068 & 0.9124 & & & \\
\hline $\mathrm{R}$ & 0.0217 & 0.0329 & 0.0267 & & & \\
\hline
\end{tabular}


A
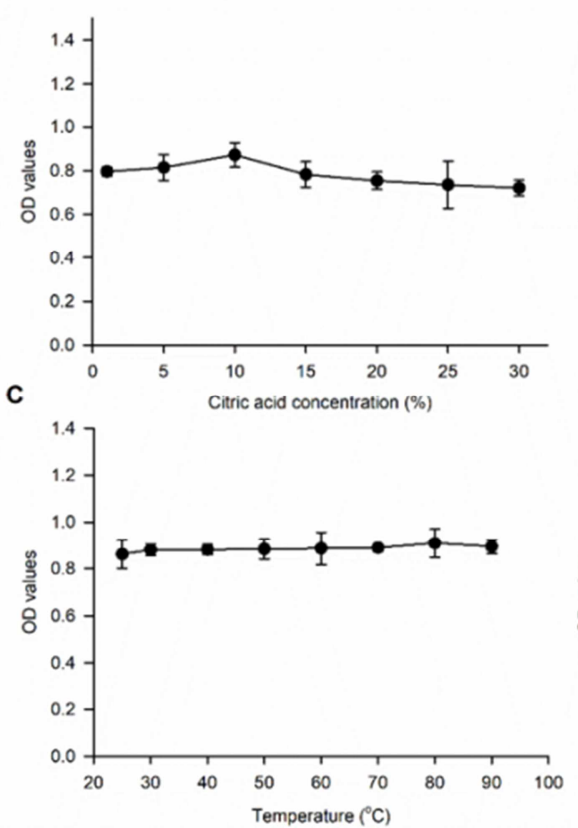

B
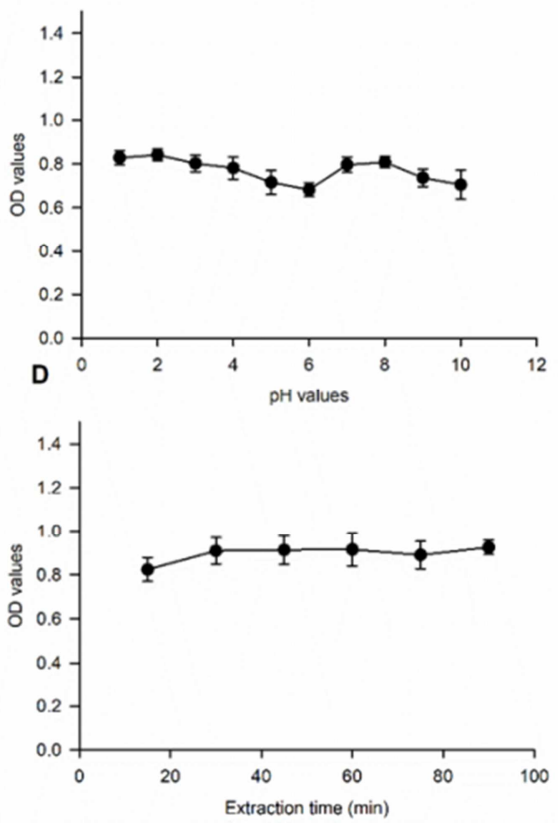

Figure 2. Extraction process and stability of red pigment from red plumeria using different citric acid concentration (A), pH values (B), and temperature (C) and extraction time (D). Means are values $\pm S E(n=3)$.

Among the measurement results of the orthogonal test, i.e., the three influencing factors of extractant concentration (A), extraction temperature (B), and extraction time (C), the effect level of the extraction effect of red pigment on the red plumeria was ranked as: extraction temperature (B) > extraction time $(\mathrm{C})>$ extractant concentration (A) (Table 8). The optimal extraction combination of red plumeria on red pigment is the $10 \%$ citric acid, $80^{\circ} \mathrm{C}$, and 90 min extraction time.

\subsection{Stability of Pigments with Different Environmental Stimulus}

The absorbance values for red pigment of red frangipani under different conditions, gradually decreased on days $1 \sim 4$, but suddenly increased on the 5th day, and then declined continuously (Figure 3A). The overall increase or decrease in light conditions is more pronounced than that under dark conditions. This suggests that with the extension of the storage time, the red pigment of red plumeria is very likely continued to degrade, and other substances will appear first and then gradually degrade. The absorption value of the red pigment of red frangipani that has not been placed under light conditions is extremely significant, compared to the absorption values of other red plumeria flowers that have been placed for a period of time (Table 9). The absorption value of the red pigment of the red frangipani placed on the 3rd day under dark conditions was only significant on the days of 0,1 , and 2 . Under light conditions, the dark pink solution faded to light pink during 7 days storage. The treatment in dark conditions for 7 days faded from the dark pink solution to pink. Our findings as mentioned above show that the red pigment of red frangipani is relatively stable under dark conditions, and other substances may be produced during the storage process. Therefore, it is essential to pay great attention to protect the pigment from light during exaction process.

As shown in Figure 3B, when the $\mathrm{pH}$ is maintained between 1 and 3 , the light absorption value of the pigment decreases continuously, while given that $\mathrm{pH}$ is higher than 4 , there are two absorption peaks. This reveals that the changes of $\mathrm{pH}$ lead to the alteration of substance in the solution. There is a significant difference in $\mathrm{pH}$ within each absorption peak (Table 10). The findings documented above show that the anthocyanin of red egg should be kept at proper $\mathrm{pH}$ value, when it is developed and used.

Table 9. Statistical analysis on red pigment solution of red egg flower in light and dark environment.

\begin{tabular}{lllll}
\hline \multirow{2}{*}{ Days (d) } & Light & Color & 5\% sig. levels & 1\% sig. levels \\
\cline { 2 - 5 } & Absorbance & Dark pink & a & A \\
\hline 0 & $0.9227 \pm 0.0035$ & Dark pink & b & B \\
5 & $0.8370 \pm 0.0010$ & Pink & b & B \\
2 & $0.8337 \pm 0.0042$ & Dark pink & b & CD \\
6 & $0.8317 \pm 0.0078$ & Light pink & c & D \\
3 & $0.8147 \pm 0.0045$ & Dark pink & c & E \\
4 & $0.8077 \pm 0.0090$ & Pink & d & F \\
7 & $0.7893 \pm 0.0115$ & Light pink & e & \\
\hline
\end{tabular}


Table 9. Continued.

\begin{tabular}{|c|c|c|c|c|}
\hline \multirow{2}{*}{ Days (d) } & \multicolumn{4}{|l|}{ Darkness } \\
\hline & Absorbance & Color & $5 \%$ sig. levels & $1 \%$ sig. levels \\
\hline 0 & $0.9223 \pm 0.0021$ & Dark pink & $\mathrm{a}$ & A \\
\hline 1 & $0.9193 \pm 0.0015$ & Dark pink & $a b$ & A \\
\hline 5 & $0.9173 \pm 0.0040$ & Pink & $a b$ & A \\
\hline 2 & $0.9167 \pm 0.0031$ & Dark pink & $\mathrm{ab}$ & A \\
\hline 6 & $0.9143 \pm 0.0032$ & Pink & $\mathrm{b}$ & A \\
\hline 3 & $0.8997 \pm 0.0093$ & Dark pink & $\mathrm{c}$ & B \\
\hline 4 & $0.8893 \pm 0.0021$ & Dark pink & d & $\mathrm{C}$ \\
\hline
\end{tabular}

Table 10. Statistical analysis on difference significance of absorbance value of pigment solution after adding different pH solutions.

\begin{tabular}{llll}
\hline $\mathbf{p H}$ & Absorbance & $\mathbf{5 \%}$ sig. levels & $\mathbf{1 \%}$ sig. levels \\
\hline 5 & $0.6337 \pm 0.0025$ & $\mathrm{a}$ & $\mathrm{A}$ \\
1 & $0.6310 \pm 0.0030$ & $\mathrm{ab}$ & $\mathrm{A}$ \\
6 & $0.6260 \pm 0.0026$ & $\mathrm{bc}$ & $\mathrm{AB}$ \\
9 & $0.6217 \pm 0.0031$ & $\mathrm{~cd}$ & $\mathrm{BC}$ \\
4 & $0.6197 \pm 0.0042$ & $\mathrm{~d}$ & $\mathrm{BC}$ \\
7 & $0.6167 \pm 0.0064$ & $\mathrm{~d}$ & $\mathrm{C}$ \\
2 & $0.6163 \pm 0.0015$ & $\mathrm{~d}$ & $\mathrm{CD}$ \\
10 & $0.6087 \pm 0.0040$ & $\mathrm{e}$ & $\mathrm{DE}$ \\
3 & $0.6073 \pm 0.0021$ & $\mathrm{e}$ & $\mathrm{E}$ \\
8 & $0.6067 \pm 0.0021$ & $\mathrm{e}$ & $\mathrm{E}$ \\
\hline
\end{tabular}

Table 11. Statistical analysis on difference of absorbance values of pigment solution after adding different concentrations $\mathrm{NaHSO}_{3}$ solution

\begin{tabular}{|c|c|c|c|c|}
\hline Con. reducing agent $(\mathrm{mol} / \mathrm{L})$ & Absorbance & Solution color & $5 \%$ sig. levels & $1 \%$ sig. levels \\
\hline 0.25 & $1.5330 \pm 0.0026$ & \multirow{6}{*}{$\begin{array}{l}\text { Colorless } \\
\text { Obvious changes }\end{array}$} & $\mathrm{a}$ & A \\
\hline 0.20 & $1.5050 \pm 0.0062$ & & $\mathrm{~b}$ & $\mathrm{~B}$ \\
\hline 0.15 & $1.4943 \pm 0.0053$ & & $\mathrm{c}$ & $\mathrm{B}$ \\
\hline 0.10 & $1.4480 \pm 0.0025$ & & d & $\mathrm{C}$ \\
\hline 0.05 & $1.2830 \pm 0.0053$ & & e & $\mathrm{D}$ \\
\hline 0.00 & $0.9130 \pm 0.0020$ & & $\mathrm{f}$ & $\mathrm{E}$ \\
\hline
\end{tabular}

The absorbance values of red pigment of red egg flower rises with the enhanced $\mathrm{NaHSO}_{3}$ concentration, and the increase of absorbance value slows down with the increased concentration of $\mathrm{NaHSO}_{3}$ (Figure 3C). As seen in Table 11, each treatment with $\mathrm{NaHSO}_{3}$ of different concentrations has significant difference, compared with the control group, while the color change of the solution is not obvious. The results showed that the absorbance values of red pigment increased; however, the color did not change obviously after $\mathrm{NaHSO}_{3}$ was added, hence the reducing agent had little effect on the stability of red pigment.

The red plumeria red pigment's absorbance value increases with promoted $\mathrm{H}_{2} \mathrm{O}_{2}$ concentration, and appear to be a plateau at $15 \sim 20 \% \mathrm{H}_{2} \mathrm{O}_{2}$ concentration (Figure 3D). The absorbance of solutions when added with various concentrations of $\mathrm{H}_{2} \mathrm{O}_{2}$ is extremely significant, compared to the control group (Table 12). In addition, with the increase of the added $\mathrm{H}_{2} \mathrm{O}_{2}$ concentration, the extraction solution gradually faded from dark pink to colorless. Therefore, following increase in the concentration of $\mathrm{H}_{2} \mathrm{O}_{2}$, the absorbance of the pigment also increases simultaneously, but the color of the solution gradually becomes lighter. This is very likely due to the fact that $\mathrm{H}_{2} \mathrm{O}_{2}$ reacts with the red pigment of red plumeria, indicating that the pigment has weak oxidation resistance and should be prevented from incubating with the oxidizing agent.

Table 12. Statistical analysis on the difference of absorbance value of pigment solution after adding different concentration of $\mathrm{H}_{2} \mathrm{O}_{2}$.

\begin{tabular}{|c|c|c|c|c|}
\hline Con. oxidants (\%) & Absorbance & Solution color & $5 \%$ sig. levels & $1 \%$ sig. levels \\
\hline 20 & $1.5897 \pm 0.0051$ & \multirow{6}{*}{ Faded from dark pink to colorless } & a & A \\
\hline 16 & $1.5400 \pm 0.0046$ & & $\mathrm{~b}$ & B \\
\hline 12 & $1.4630 \pm 0.0026$ & & $\mathrm{c}$ & $\mathrm{C}$ \\
\hline 8 & $1.2817 \pm 0.0038$ & & $\mathrm{~d}$ & $\mathrm{D}$ \\
\hline 4 & $1.0557 \pm 0.0025$ & & e & $\mathrm{E}$ \\
\hline 0 & $0.9150 \pm 0.0092$ & & $\mathrm{f}$ & $\mathrm{F}$ \\
\hline
\end{tabular}



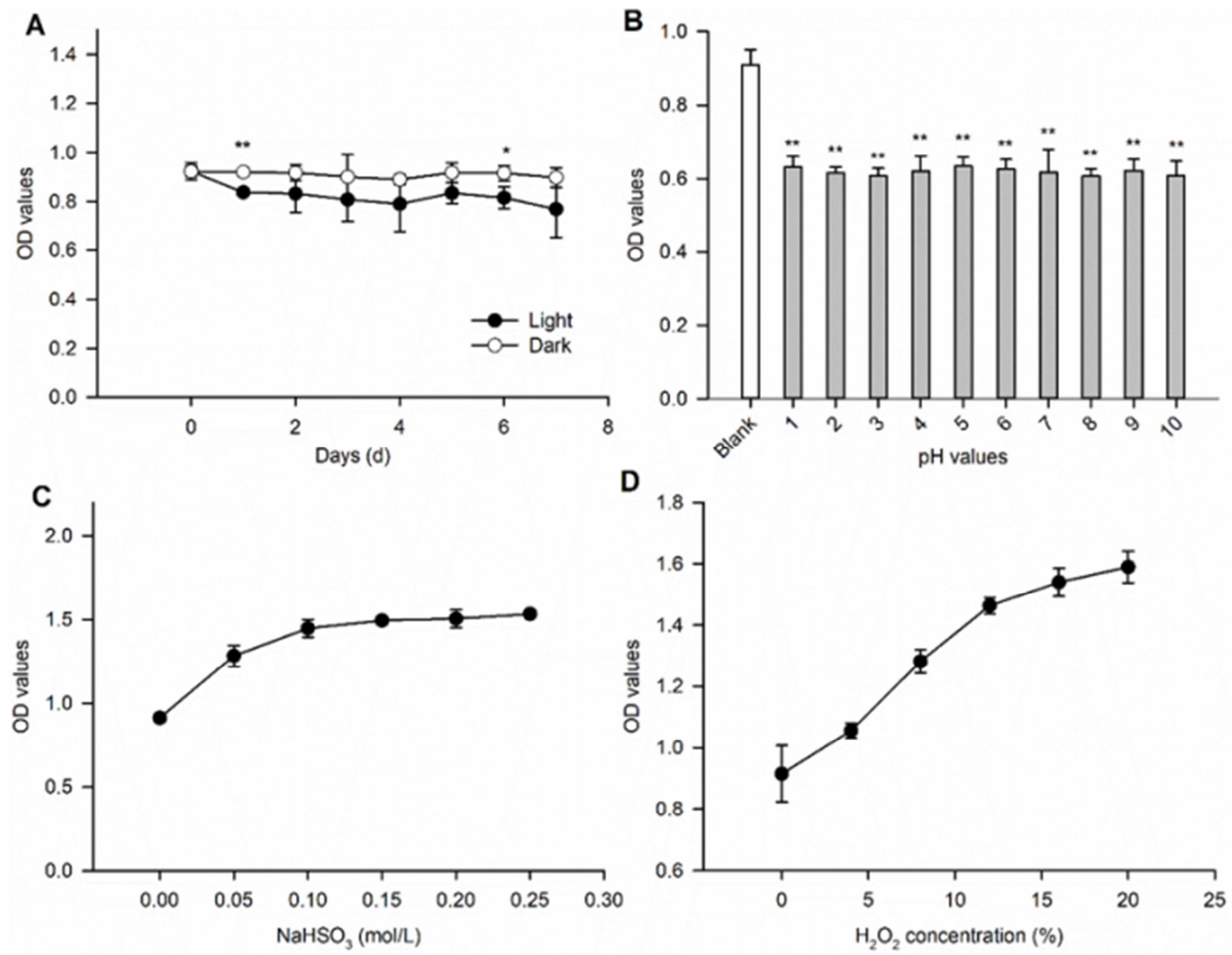

Figure 3. Effects of factors on red pigment of red egg flower. A, light and dark; $B$, different $p H$ values; $C$, reducing agent; $D$, oxidant. For panels $A$, $B$, means are values $\pm S E(n=3)$. Symbols “*”, “**”, and “***” represent $P$ value $<0.05,0.01$ and 0.001 , respectively, according to Student's t-test.

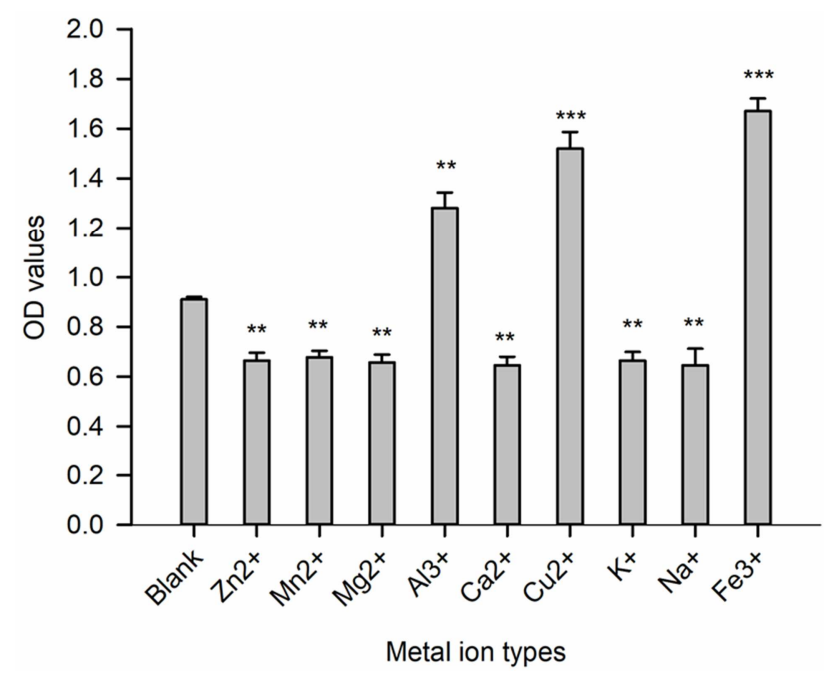

Figure 4. Effect of metal ions on red pigment of red egg flower. Means are values $\pm S E(n=3)$. Symbols “*”, “**”, and “***” represent $P$ value $<0.05$, 0.01 and 0.001 , respectively, according to Student's t-test.
Compared with the control (CK), the absorption values of the pigment extraction solution increased after adding $\mathrm{Al}^{3+}$, $\mathrm{Cu}^{2+}, \mathrm{Fe}^{3+}$ (Figure 4). The absorption values of the pigment extraction solution increased significantly; while adding $\mathrm{Mn}^{2+}$, $\mathrm{Zn}^{2+}, \mathrm{K}^{+}, \mathrm{Mg}^{2+}, \mathrm{Na}^{+}, \mathrm{Ca}^{2+}$ Compared with the control, the absorbance value of the pigment extraction solution is reduced. As shown in Table 13, after adding metal ions, the primary color of the metal ion solution replaces the color of the extraction solution, indicating that the addition of metal ions has a direct effect on the color of the extraction solution. There were significant differences among $\mathrm{Mn}^{2+}, \mathrm{Al}^{3+}, \mathrm{Cu}^{2+}$, and $\mathrm{Fe}^{3}$ ${ }^{+}$, while there was no significant difference between $\mathrm{Zn}^{2+}, \mathrm{K}^{+}$, and $\mathrm{Mg}^{2}$, and it is the case (no significant difference) between $\mathrm{Na}^{+}$and $\mathrm{Ca}^{2+}$, although it was significant difference between each metal ion and the control. We hence proposed that each metal ion has a great influence on the pigment extraction, and it is highly recommended that extracting the pigment solution should avoid directly contacting with these metal ions. 
Table 13. Statistical analysis on the difference of absorbance value of red egg pigment solution after adding various metal ions.

\begin{tabular}{llllll}
\hline Metal ion & Metal color & Mean Absorbance & Solution color after adding metal ion & $\mathbf{5 \%}$ sig. levels & 1\% sig. levels \\
\hline $\mathrm{Fe}^{3+}$ & Yellow & $1.6707 \pm 0.0050$ & Light yellow & $\mathrm{a}$ & $\mathrm{A}$ \\
$\mathrm{Cu}^{2+}$ & Blue & $1.5197 \pm 0.0067$ & Light blue & $\mathrm{b}$ & $\mathrm{C}$ \\
$\mathrm{Al}^{3+}$ & Colorless & $1.2810 \pm 0.0062$ & Colorless & $\mathrm{d}$ & $\mathrm{C}$ \\
$\mathrm{CK}$ & Colorless & $0.9110 \pm 0.0010$ & Pink & $\mathrm{e}$ & $\mathrm{D}$ \\
$\mathrm{Mn}^{2+}$ & Colorless & $0.6770 \pm 0.0026$ & Colorless & $\mathrm{f}$ & $\mathrm{E}$ \\
$\mathrm{Zn}^{2+}$ & Colorless & $0.6647 \pm 0.0031$ & Colorless & $\mathrm{f}$ & $\mathrm{F}$ \\
$\mathrm{K}^{+}$ & Colorless & $0.6643 \pm 0.0035$ & Colorless & $\mathrm{F}$ & $\mathrm{F}$ \\
$\mathrm{Mg}^{2+}$ & Colorless & $0.6573 \pm 0.0031$ & Colorless & $\mathrm{g}$ & $\mathrm{G}$ \\
$\mathrm{Na}^{+}$ & Colorless & $0.6460 \pm 0.0066$ & Colorless & $\mathrm{g}$ & $\mathrm{G}$ \\
$\mathrm{Ca}^{2+}$ & Colorless & $0.6447 \pm 0.0035$ & Colorless & \\
\hline
\end{tabular}

The absorbance of the pigment solution increases with enhanced soluble starch concentration (Figure 5). The absorbance values of the pigment solution first gradually increases with the sucrose concentration, when the concentration reaches $2 \%$, the absorbance value decreases, and then the absorbance value rises again (Figure 5). The absorbance value of the pigment solution first gradually increases with the salt concentration, and it changes when the concentration reaches up to $2 \%$, and the absorbance value begins to decrease.

There is a significant difference between the absorbance values of sucrose pigment solutions, when adding with different concentrations and the control group (Table 14). Similarly, there is a significant difference between the absorbance value of the salt solution with different concentrations and the control group (Table 15). We also found that except for the soluble starch concentration of $1 \%$, there is a significant difference in absorbance between the control group and other pigment solutions treated with different concentrations (Table 16). The absorbance of soluble starch differs significantly between different concentrations. Collectively, the addition of different concentrations of sucrose, table salt, and soluble starch all changed the color of the pigment solution and became colorless. In summary, none of sucrose, salt, and soluble starch can be mixed with red plumeria red pigment to make commodities.

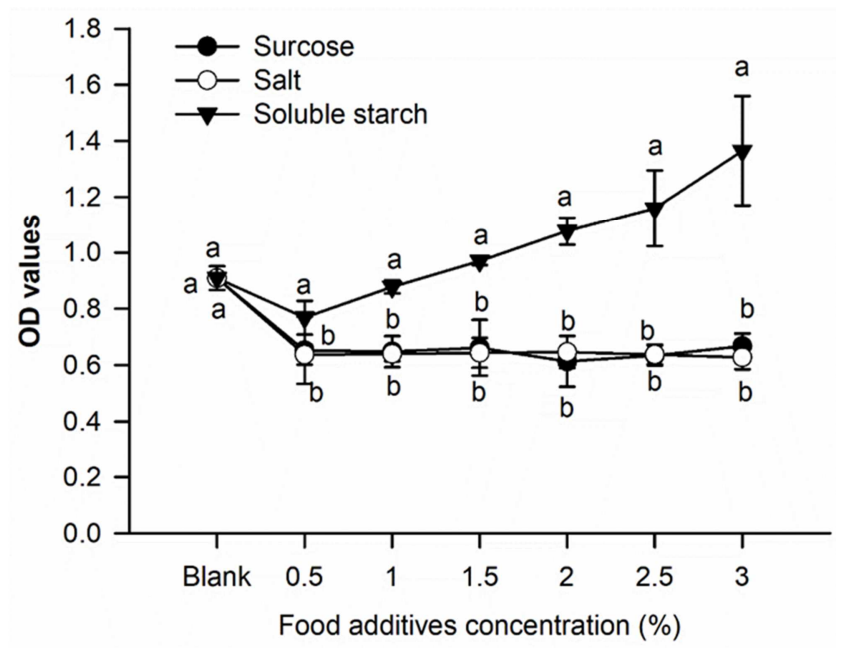

Figure 5. Effect of common food additives on pigment extraction. Means are values $\pm S E(n=3)$. Different alphabet letters represent significant differences among different food additive for each concentration at $P$ value $<0.05$ according to one-way ANOVA.

Table 14. Statistical analysis on the difference of absorbance value of pigment solution with different concentration of sucrose.

\begin{tabular}{lllll}
\hline Con. (\%) & Solution color & Mean Absorbance & 5\% sig. levels & 1\% sig. levels \\
\hline CK & Pink & $0.9093 \pm 0.0042$ & $\mathrm{a}$ & $\mathrm{A}$ \\
3.0 & Colorless & $0.6677 \pm 0.0045$ & $\mathrm{~b}$ & $\mathrm{~B}$ \\
1.5 & Colorless & $0.6617 \pm 0.0099$ & $\mathrm{bc}$ & $\mathrm{BC}$ \\
0.5 & Colorless & $0.6527 \pm 0.0119$ & $\mathrm{~cd}$ & $\mathrm{BCD}$ \\
1.0 & Colorless & $0.6483 \pm 0.0055$ & $\mathrm{~d}$ & $\mathrm{CD}$ \\
2.5 & Colorless & $0.6343 \pm 0.0035$ & $\mathrm{e}$ & $\mathrm{D}$ \\
2.0 & Colorless & $0.6137 \pm 0.0099$ & $\mathrm{f}$ & $\mathrm{E}$ \\
\hline
\end{tabular}

Table 15. Statistical analysis on the difference of absorbance value of pigment solution after adding different concentration of salt solution.

\begin{tabular}{lllll}
\hline Con. (\%) & Solution color & Mean Absorbance & 5\% sig. levels & 1\% sig. levels \\
\hline CK & Pink & $0.9093 \pm 0.0042$ & a & A \\
2.0 & Colorless & $0.6467 \pm 0.0057$ & b & B \\
1.5 & Colorless & $0.6440 \pm 0.0053$ & bc & B \\
1.0 & Colorless & $0.6397 \pm 0.0025$ & bc & B \\
2.5 & Colorless & $0.6377 \pm 0.0035$ & c & BC \\
0.5 & Colorless & $0.6373 \pm 0.0035$ & c & BC \\
3.0 & Colorless & $0.6277 \pm 0.0042$ & d & C \\
\hline
\end{tabular}


Table 16. Statistical analysis on the difference of absorbance value of pigment solution after adding different concentration of soluble starch solution.

\begin{tabular}{lllll}
\hline Con. (\%) & Solution color & Mean Absorbance & 5\% sig. levels & 1\% sig. levels \\
\hline 3.0 & Colorless & $1.3650 \pm 0.0195$ & $\mathrm{a}$ & $\mathrm{A}$ \\
2.5 & Colorless & $1.1593 \pm 0.0136$ & $\mathrm{~b}$ & $\mathrm{~B}$ \\
2.0 & Colorless & $1.0773 \pm 0.0549$ & $\mathrm{c}$ & $\mathrm{C}$ \\
1.5 & Colorless & $0.9703 \pm 0.0015$ & $\mathrm{~d}$ & $\mathrm{D}$ \\
$\mathrm{CK}$ & Pink & $0.9093 \pm 0.0042$ & $\mathrm{e}$ & $\mathrm{E}$ \\
1.0 & Colorless & $0.8783 \pm 0.0023$ & $\mathrm{e}$ & $\mathrm{E}$ \\
0.5 & Colorless & $0.7687 \pm 0.0060$ & $\mathrm{f}$ & $\mathrm{F}$ \\
\hline
\end{tabular}

\section{Discussion}

It is extensive reported that effective extraction for the pigment can be achieved through solvent extraction method [14-16]. In this study, we applied this approach with constraining the principle of single variable. The effects of different extractants, concentrations, $\mathrm{pH}$ conditions, temperature, and time on the extraction of red plumeria red pigment were systematically studied and analyzed. In order to determine whether there is an interaction between the extraction factors, we further employed an orthogonal test to screen out the optimal pigment extraction conditions. The optimal conditions for extracting red pigment from red frangipani are screened by timely measuring the absorbance value, and eventually the stability of the extracted red pigment from red frangipani is discussed.

Extensive studies have shown that the red anthocyanins in the strong acid solution, the pigment solution appear as the color as original shows $[17,18]$. When the $\mathrm{pH}$ value is greater than 4 , the pigment is red-shifted and the color becomes lighter. In contrast, when the $\mathrm{pH}$ is greater than 7 , the pigment gradually turns to be orange yellow, yellow-green to yellow. Therefore, it is reasonable to propose that red pigment in red plumeria contains anthocyanins.

\subsection{The Best Extraction Process of Red Pigment in Red Plumeria}

In current study, in order to facilitate the approachable operation steps and further improve the extraction effects, the petals were dried and ground into a fine powder with a grinder. As used in many studies regarding extractant, their concentration, $\mathrm{pH}$, extraction temperature and time are generally used as screening conditions for mining optimal extraction process $[19,20]$. Among various options of solvents, red plumeria red pigment is insoluble in ethyl acetate, acetone, and absolute ethanol, but soluble in distilled water, $30 \%$ ethanol, $50 \%$ ethanol, and $10 \%$ citric acid. We here proved that the extraction speed of the pigments extracted with distilled water, ethanol, and citric acid is fast and sufficient.

In the research of other pigment extraction, water and ethanol are commonly used as extractants. For examples, water can be used as an extractant for natural gardenia yellow pigment [21], while $\sim 60 \%$ ethanol was used to extract the pigment of red orange peel [22]. They found that the extraction effect was the best, but citric acid is rarely used for pigment extraction, and is generally used for color preservation of pigments. When the absorbance value was measured, it was found that the color of the solution was more obvious than that of the distilled water extract. Strikingly, the extract of the pigment extracted with distilled water had the highest absorbance value, and the citric acid pigment extract was obviously stable [23]. These results suggest that citric acid may play an important role in anti-oxidation and other color-preserving functions. Meanwhile, compared with alcohol-soluble aqueous solution, the cost of acidic solution is lower and closer to the ingredients of the food itself, therefore, we proposed that citric acid is finally selected as the extractant.

In terms of the optimal $\mathrm{pH}$ conditions, it was found that the $\mathrm{pH}$ changes its color by affecting the structure of anthocyanins [24]. The pigment can be extracted under strongly acidic conditions, and the resulting pigment solution maintains the original red plumeria color. As increases in the $\mathrm{pH}$ of the extractant, the higher the $\mathrm{pH}$, the rate of anthocyanins degraded faster, leading to more obvious the color change of the pigment [25]. In our study, we found that adding other reagents to adjust the $\mathrm{pH}$ of the solvent would change the concentration and composition of the extractant, which reduces the effect of citric acid on extracting pigments. Therefore, unadjusted $\mathrm{pH}$ extractant could be the best option in this case. During the pigment extraction in response to temperature, we found that the optimal extraction temperature is $80^{\circ} \mathrm{C}$, indicating that the pigment is relatively heat-resistant and can be developed and applied to general food and beverage additives.

\subsection{Stability Analysis of Red Pigment in Red Plumeria}

Followed by prolong incubation time, as observed in our study, natural pigments turns to be degrade, and this process is further accelerated under light conditions. The absorbance of the pigment solution gradually decreased within 4 days, and the color gradually faded. This may be related to an increase in light exposure time, the increase in the number of photons, the increase in the number of excited pigment molecules, and the continuous photodegradation reaction $[26,27]$. Therefore, when using pigments, it is necessary to prevent direct sunlight as much as possible. Interestingly, the absorbance value suddenly increased, and then continued to decrease at the $5^{\text {th }}$ day. Meanwhile, it was found that there were translucent impurities in the pigment solution in the later stage. It is speculated that there is some kind of bacteria, therefore it is highly recommended that it should be sterilized before it is 
used in practice.

In this study, the red plumeria red pigment solution's absorbance value changes continuously with the change of $\mathrm{pH}$ value. This is due to the alteration of $\mathrm{pH}$ of the solution, as well as the chemical structure of anthocyanin. Anthocyanins exist in the form of yellow salt cations, quinoid bases, pseudoalkali, and chalcone in the aqueous solution. The above four forms could be reversibly changed due to the alteration of $\mathrm{pH}$ regimes of the aqueous solution. Meanwhile, the color of the solution also changes due to alteration of composition [28]. Therefore, the pigment solution should be stored under suitable acid-base conditions.

In addition, the red pigment of red frangipani had better resistance to reductant agents, as observed in our study; however, it is feasible to oxidants. During the study of the stability of $\mathrm{H}_{2} \mathrm{O}_{2}$ to the red plumeria red pigment solution, the color of the solution gradually faded. This is because the pretense salt structure of anthocyanins is susceptible to nucleophilic attack by oxidants, and becomes unstable, non-ionic, namely epicatechin, and fades to colorless [29, 30]. Therefore, it is essential to avoid the simultaneous use of oxidant during pigment storage.

Interestingly, we found that all kinds of metal ions and common food additives broke the stability of the red pigment of red plumeria. For example, $\mathrm{Al}^{3+}, \mathrm{Zn}^{2+}, \mathrm{Cu}^{2+}, \mathrm{Fe}^{3+}$ characterized with large molecular weight, high atomic valence states, therefore, metal ions with metal activity will react with natural pigments, which leads to the fade or precipitation of pigments. Therefore, $\mathrm{K}^{+}, \mathrm{Ca}^{2+}, \mathrm{Na}^{+}$and other metal ions do not react with it [22]. To explain the replacement of the color of the pigment solution by the primary color of the metal ion solution, we proposed that the pigment easily reacts with the metal ion, or it may be due to the interference of the color of the metal ion aqueous solution that can exhibit color. However, it requires further studied to prove whether there are other metal ions or food additives that can be stored more stably with the pigment.

Taken together, the red pigment of red frangipani has certain stability with a great development prospect. If the pigment is to be used in actual production, it should also be comprehensively studied to improve the properties of other aspects to ensure its population-free, effectiveness and high-extraction efficiency.

\section{Conclusion}

The red pigment of red plumeria can be dissolved in water and alcohol, rather than organic solvents, therefore, it is a water-soluble pigment with anthocyanin pigments, with the absorption peak at $300 \mathrm{~nm}$. The optimal combination of pigment extraction is to use citric acid with a concentration of $10 \%$ as the extractant, the temperature is $80{ }^{\circ} \mathrm{C}$, and the time is $90 \mathrm{~min}$. The red pigment of red frangipani is light-sensitive, but resistance to reductant agent, rather than to oxidation. The red pigment of red frangipani changes with various $\mathrm{pH}$ value as well as metal ion, including $\mathrm{Al}^{3+}, \mathrm{Cu}^{2+}, \mathrm{Fe}^{3+}, \mathrm{Mn}^{2+}, \mathrm{Zn}^{2+}, \mathrm{K}^{+}$, $\mathrm{Mg}^{2+}, \mathrm{Na}^{+}$, and $\mathrm{Ca}^{2+}$. We also proposed that sucrose, salt and soluble starch should not be mixed when extracting red plumeria red pigment.

\section{Author Contributions}

Conceptualization, T. W., Y. Y.; Methodology, T. W., Y. Y.; Investigation, Q. L., B. C.; Writing, T. W.; Funding Acquisition, T. W.; Resources, T. W.; Supervision, T. W.

\section{Declaration of Interest}

The authors declare that they have no competing interests.

\section{Acknowledgements}

This work was supported by Pilot project for comprehensive reform of majors (GDOU2013040402); Ministry of Education's outstanding agricultural and forestry talent training program (horticulture, GDOU2014041204); national agricultural science and education cooperation talent cultivation base (GDOU2013040301); horticulture and gardening professional practical skills agricultural and forestry talent training model reform pilot (GDOU2014041208); Pilot Comprehensive Reform of Horticulture (GDOU2013040402). We thank Hainan Zhongkang Omics Biotech. Co. Ltd for technical service on bioinformatics analysis.

\section{References}

[1] Chen, C.-C.; Lin, C.; Chen, M.-H.; Chiang, P.-Y. Stability and Quality of Anthocyanin in Purple Sweet Potato Extracts. Foods (Basel, Switzerland) 2019, 8, 393.

[2] Pandey, R.; Upadhyay, S. Food Additive. In; 2012; pp. 1-30 ISBN 978-953-51-0067-6.

[3] Rodriguez-Amaya, D. B. Natural food pigments and colorants. Curr. Opin. Food Sci. 2016, 7, 20-26.

[4] Xu, W.; Yu, J.; Feng, W.; Su, W. Selective Extraction of Gardenia Yellow and Geniposide from Gardenia jasminoides by Mechanochemistry. Molecules 2016, 21, 540.

[5] Ge, X.; Wan, Z.; Song, N.; Fan, A.; Wu, R. Efficient methods for the extraction and microencapsulation of red pigments from a hybrid rose. J. Food Eng. 2009, 94, 122-128.

[6] Rath, T.; Kawollek, M. Robotic harvesting of Gerbera Jamesonii based on detection and three-dimensional modeling of cut flower pedicels. Comput. Electron. Agric. 2009, 66, 8592.

[7] Zhang, Y.; Yin, C.; Kong, L.; Jiang, D. Extraction optimisation, purification and major antioxidant component of red pigments extracted from Camellia japonica. Food Chem. 2011, 129, 660 664.

[8] Zhu, F.; Wang, X.; Fan, W.; Qu, L.; Qiao, M.; Yao, S. Assessment of potential health risk for arsenic and heavy metals in some herbal flowers and their infusions consumed in China. Environ. Monit. Assess. 2013, 185, 3909-3916. 
[9] Marias, D. E.; Meinzer, F. C.; Still, C. Impacts of leaf age and heat stress duration on photosynthetic gas exchange and foliar nonstructural carbohydrates in Coffea arabica. Ecol. Evol. 2017, 7, 1297-1310.

[10] Zhang, H.; Jim, C. Y. Species diversity and performance assessment of trees in domestic gardens. Landsc. Urban Plan. 2014, 128, 23-34.

[11] Murashige, T. The Deciduous Behavior of a Tropical Plant, Plumeria acuminata. Physiol. Plant. 1966, 19, 348-356.

[12] Woodson, R. E. (Robert E. Studies in the Apocynaceae. VII. An Evaluation of the Genera Plumeria L. and Himatanthus Willd. Ann. Missouri Bot. Gard. 1938, 25, 189-224.

[13] Nabi, J.; Narwariya, P. COMPREHENSIVE OVERVIEW OF PLUMERIA OBTUSA. World J. Pharm. Res. 2020, 6, 664 676.

[14] Saseendran, S. A revised method for pigment extraction from marine nannoplanktonic algal cultures. J. Algal Biomass Utln. 2013, 4, 47-52.

[15] Hosikian, A.; Lim, S.; Halim, R.; Danquah, M. K. Chlorophyll Extraction from Microalgae: A Review on the Process Engineering Aspects. Int. J. Chem. Eng. 2010, 2010, 391632.

[16] Szymczak-Żyła, M. Analysis of chloropigments in marine sediments using accelerated solvent extraction (ASE). Limnol. Oceanogr. Methods 2016, 14, 477-489.

[17] García-Viguera, C.; Bridle, P. Influence of structure on colour stability of anthocyanins and flavylium salts with ascorbic acid. Food Chem. 1999, 64, 21-26.

[18] Castañeda-Ovando, A.; Galán-Vidal, C. A.; Contreras-López, E.; Páez-Hernández, M. E. Purification of Anthocyanins with o-Dihydroxy Arrangement by Sorption in Cationic Resins Charged with $\mathrm{Fe}(\mathrm{III})$. J. Chem. 2014, 2014, 367236.

[19] Shao, J.; Cheng, Y.; Yang, C.; Zeng, G.; Liu, W.; Jiao, P.; He, $\mathrm{H}$. Efficient removal of naphthalene-2-ol from aqueous solutions by solvent extraction. J. Environ. Sci. 2016, 47, 120 129 .

[20] Li, B.; Wu, C.; Hu, D.; Xu, J.; Zhang, T.; Tong, J.; Fang, X. Copper extraction from the ammonia leach liquor of spent lithium ion batteries for regenerating $\mathrm{LiNi} 0.5 \mathrm{Co} 0.5 \mathrm{O} 2$ by co-precipitation. Hydrometallurgy 2020, 193, 105310.

[21] Lyu, J.; Qian, G.-F.; Chen, L.; Liu, H.; Xu, H.-X.; Xu, G.-R.; Zhang, B. B.; Zhang, C. Efficient Biosynthesis of Natural Yellow Pigments by Monascus purpureus in a Novel Integrated Fermentation System. J. Agric. Food Chem. 2018, 66.

[22] Habbal, H.; Karabet, F. Determination of the Optimum Extraction Conditions of Carotenoid Pigment from Orange Peel by Response Surface Methodology. 2020, 11, 1141-1149.

[23] Wang, B.-S.; Li, B.-S.; Zeng, Q.-X.; Liu, H.-X. Antioxidant and free radical scavenging activities of pigments extracted from molasses alcohol wastewater. Food Chem. 2008, 107, 1198-1204.

[24] Wahyuningsih, S.; Wulandari, L.; Wartono, W.; Munawaroh, H.; Ramelan, A. The Effect of $\mathrm{pH}$ and Color Stability of Anthocyanin on Food Colorant The Effect of $\mathrm{pH}$ and Color Stability of Anthocyanin on Food Colorant. IOP Conf. Ser. Mater. Sci. Eng. 2016, 193.

[25] Reyes, L. F.; Cisneros-Zevallos, L. Degradation kinetics and colour of anthocyanins in aqueous extracts of purple- and red-flesh potatoes (Solanum tuberosum L.). Food Chem. 2007, 100, 885-894.

[26] MacCallum, J. R. 18 - Photodegradation. In; Allen, G., Bevington, J. C. B. T.-C. P. S. and S., Eds.; Pergamon: Amsterdam, 1989; pp. 529-537 ISBN 978-0-08-096701-1.

[27] Hsieh, P.; Pedersen, J. Z.; Albertano, P. Generation of reactive oxygen species upon red light exposure of cyanobacteria from Roman hypogea. Int. Biodeterior. Biodegradation 2013, 84, $258-265$.

[28] Sagsoz, N.; Yanıkoğlu, N.; Ulu, H.; BAYINDIR, F. Color Changes of Polyamid and Polymetyhl Methacrylate Denture Base Materials. Open J. Stomatol. 2014, 04, 489-496.

[29] Boulton, R. The Copigmentation of Anthocyanins and Its Role in the Color of Red Wine: A Critical Review. Am. J. Enol. Vitic 2001,522 .

[30] Jackman, R.; Yada, R.; TUNG, M.; Speers, R. Anthocyanins as food colorants - A review. J. Food Biochem. 1987, 11, 201247. 